\title{
Analysis of Current Situation of Fancy Rope Skipping Curriculum in Regular Institutions of Higher Learning in Sichuan Province
}

\author{
Zhang Yongmao \\ Southwest Petroleum University, Chengdu Sichuan 610500
}

\begin{abstract}
This paper adopts the research methods such as literature material method, questionnaire investigation method, expert interview method and mathematical statistics to investigate and study the conditions of fancy rope skipping curriculum in 22 universities in Sichuan. The research shows that the university teachers highly recognize the fancy rope skipping curriculum; construction of teaching resources should be strengthened; cultivation of the professional teaching staffs should be strengthened; in terms of teaching materials, more premium teaching materials with high pertinence and professionalism are needed; the promotion and implementation of the curriculum system of fancy rope skipping should be boosted in different steps and stages; cultivation of the professional teachers should be enlarged; related scientific research of the curriculum system of fancy rope skipping should be strengthened.
\end{abstract}

Key Words: Sichuan Province; regular institutions of higher learning; fancy rope skipping; the current situation; analysis

\section{INTRODUCTION}

Rope skipping is a traditional sports event in our country, which was invented in the Tang Dynasty; it can be regarded as an event of competitive sports and also a recreational mode, which is of great value in fitness, recreation and cultivating the tastes. Rope skipping is a simple and easy sports event for the masses. In recent years, some new actions such as the martial arts, gymnastics, dance and art gymnastics are combined into the traditional rope skipping, which is called fancy rope skipping. It is a newly emerging popular sports. It is fashionable with music accompaniment, various types and patterns and both simple and complicated actions. It is challenging and has good fitness effects. So it is popular at home and abroad with its unique charm. It is an effective aerobic exercise; it can boost the development of organs and is good for physical and mental health. In addition, it can help build the body, develop the intelligence and improve the physical quality of students. It is characteristic of 'exercising the body, the mind and figure', which accords with the characteristics of body and mind development of students in universities. Most importantly, it is better than other sports events in terms of safety and stadium. Hence it is worth promoting and popularizing and should be attached great importance to.

Fancy rope skipping curriculum is just set up in the domestic universities, which is conducted in several institutions of high learning. There are still many problems, such as the limited ability of teachers, certain difficulties, insufficient cognition and attention of the leaders etc; many aspects such as teaching contents, teaching material and teaching method should be improved. Through investigating the current situation of fancy rope skipping curriculum of 
the regular institutions of higher learning in Sichuan, this paper hopes to provide realistic evidence and support for construction and implementation of the curriculum system of fancy rope skipping of the regular institutions of higher learning in Sichuan.

\section{Research Object and Method}

\subsection{Research Object}

This paper takes the teachers and students of 22 regular institutions of higher learning of different levels and features in Sichuan as the investigation object, including Sichuan University, Sichuan Normal University, Southwest Jiaotong University, Southwest Petroleum University, Xihua University, Chengdu University, Southwestern University of Finance and Economics, University of Electronic Science and Technology of China, Chengdu University of Information Technology, Neijiang Normal University, Leshan Teachers College, Xichang College, Yibin University, China West Normal University, Chengdu Polytechnic, Southwest Medical University, Chengdu University of TCM, Chengdu University of Technology, Sichuan University of Science \& Engineering, Sichuan Agricultural University, Sichuan University of Arts and Science, Chengdu Sport University. Through comprehensive investigation of students and teachers in these 22 regular institutions of higher learning, this paper aims to study the current situation of opening and implementation of fancy rope skipping curriculum in the universities of Sichuan.

\subsection{Research Method}

2.2.1 Literature material method. In order to guarantee the pertinence and effectiveness of research, I have selected the related literature of fancy rope skipping curricula through the library of Southwest Petroleum University and Chengdu Sport University, CNKI and Wanfang
Data; I've also consulted the books and monographs of related fields and mastered the current research situation at home and abroad, thus having provided sufficient theoretical basis for this research.

2.2.2 Questionnaire investigation method. I have handed out 50 questionnaires to the teachers and 1000 to the students (500 to boys and 500 to girls) in 22 regular institutions of higher learning in Sichuan Province. I have adopted the method such as small sample resurvey method and expert logic test method to test the reliability and validity of the questionnaires so as to guarantee the scientificity and objectiveness of data. 50 questionnaires for teachers are retrieved, with the valid retrieval ratio of 100\%; 945 questionnaire for students are retrieved and the valid questionnaires are 939 (434 for boys and 505 for girls), with the valid retrieval ratio of $99.4 \%$.

2.2.3 Expert interview method. Gain the theoretical and technical support through interviewing the domestic educational and teaching experts, fancy rope skipping experts and some of the directors of sports departments of the universities so as to gain the persuasive research results.

2.2.4 Mathematical statistics method. Classify the effective questionnaires and makes statistical handling of the investigation results through SPSS.

\section{Result and Analysis}

3.1 Cognition of Teachers and Students of Universities about the Fancy Rope Skipping Curriculum 
Chart 1 Cognition Investigation Results of Cognition of Teachers and Students of Universities about the Fancy Rope Skipping Curriculum

\begin{tabular}{|c|c|c|}
\hline & Know & know \\
\hline Willing to attend & \multicolumn{2}{|l|}{ Unwilling to attend } \\
\hline Teacher & $78 \%$ & $22 \%$ \\
\hline $90 \%$ & $10 \%$ & \\
\hline Student & $81 \%$ & $19 \%$ \\
\hline $82.3 \%$ & $17.7 \%$ & \\
\hline
\end{tabular}

Through investigating fancy rope skipping curriculum of 22 universities, the attraction degree of the curriculum to students is shown in the above chart: students in universities pay much attention to fancy rope skipping curriculum. Among the investigated students, $81 \%$ of the students know something about fancy rope skipping project; most of them know it through recreational programmes, large-scale performances and gymnastic lessons in primary schools. $82.3 \%$ of the students say that if the schools open fancy rope skipping curriculum, they are willing to choose it. Statistical data show that students in universities are interested in fancy rope skipping curriculum, which shows that the fancy rope skipping attracts the students; it accords with the features of contemporary undergraduates who are fashionable. Fancy rope skipping is loved by students due to its trendy and novel style, multiple patterns and flexible representation methods, which accords with the psychological features of contemporary undergraduates.

Similarly, as is shown in Chart 1 about investigation of teachers in 22 universities, the result shows: $90 \%$ of the teachers are interested in fancy rope skipping curriculum and are willing to learn it and impart it to students. These data fully show that fancy rope skipping greatly attracts students and teachers from universities and can be widely recognized by them.

3.2 Analysis of Current Situation of Teaching Team of Fancy Rope Skipping Curriculum Investigation shows that although physical education teachers of universities go through strict training and examination, yet teachers who receive training of fancy rope skipping are severely insufficient, due to the fancy rope skipping has not been fully recognized and attached more importance to. Statistical results show that fancy rope skipping is highly recognized by teachers and students. However, teachers still lack the skills and teaching ability of fancy rope skipping curriculum, which shows that software construction such as teaching team cannot guarantee normal teaching yet.

Chart 2 Investigation Chart of Teaching Team of

Fancy Rope Skipping Curriculum $\quad \mathrm{No}=50$

Received

training Did not receive raining

Fancy Rope Skipping Curriculum

Teaching Team

44

Investigation Conditions

Proportion of the total number

$88 \%$

As the base of talent cultivation, universities must attach importance to cultivation and improvement of the qualities of teachers. Investigation result in Chart 2 shows that 12\% of the teachers have received related training of fancy rope skipping project and $88 \%$ of them have not. Meanwhile, Chart 1 shows that $90 \%$ of the teachers are willing to accept training related to fancy rope skipping, which shows that physical education teachers have active learning attitudes and that we do not provide enough opportunities of learning fancy rope skipping for teachers. On one hand, schools can make PE 
teachers learn the frontier knowledge and skills of fancy rope skipping; on the other hand, schools can provide related training so as to make the PE teachers learn from each other and boost the development of curriculum construction.

3.3 Opening Ratio and Mode of Fancy Rope Skipping Curriculum

Among the investigated schools, the opening ratio of this curriculum is not optimistic; compared with universities in other provinces, the opening ratio is relative low. It is mainly opened as the elective curriculum, extracurricular club lesson and special lecture. Elective curricula mainly face the students, especially the junior and senior students; extracurricular club is the extension of curriculum teaching; the special lecture usually invites the experts to communication with students within a small scale. Through investigation of universities of Sichuan Province, the opening ratio and mode of fancy rope skipping is not ideal.

3.4 Teaching Implementation of Fancy Skipping Curriculum

(1) Use of teaching material. Fancy rope skipping project develops in our country late and its time in universities is short, thus covering not many contents. Investigation of the schools that open the curriculum shows that all the schools own the teaching materials of compulsory curriculum of physical education; from the contents of teaching materials for the elective curriculum of physical education, the contents related to fancy rope curriculum are not comprehensive and small-sized, basically about the introduction of the project and basic skills. Among the investigated schools, only Chengdu Sport Institute and Southwest Petroleum University purchased the professional teaching material--Fancy Rope Skipping. Through investigation of the books related to fancy rope skipping in the libraries, it is seen that the source of teaching materials is limited and implementation of teaching materials is not unified. Therefore, to strengthen construction of teaching materials of fancy rope skipping is a long-term important job.

(2) Class hour. For the school that take the fancy rope skipping as the elective curriculum, the number of class hour in two years and four semesters reaches 72-144, in which theoretical curricula take up 4-8 class hours. For some schools with worse opening conditions, only one-semester elective curriculum is opened. Some provide special teaching contents in the mixed curriculum; the number of class hour of special teaching curriculum is only 18-36 and even less. The occupation ratio of class hour of fancy rope skipping remains low; many of them just use the first 10 minutes of a class hour to make students warm up.

3.5 Curriculum Teaching Venue and Equipment

Fancy rope skipping has not high requirements of venue and equipment, so it is of venue and equipment advantage. It is a sports that can be popularized and conducted in universities. At present, the venue and sports equipment of universities in Sichuan can basically satisfy the teaching of fancy rope skipping and effectively help finish the basic training and tasks of extracurricular activities. The main requirement is the stereo equipment. Through investigation of stereo equipment, $75.5 \%$ of the students are satisfied; $25.5 \%$ are not satisfied. The main reason is that the stereo equipment has small power and volume and students at the back cannot listen to music clearly. Meanwhile, the practice atmosphere of such curriculum is not that good. 


\section{Conclusion and Suggestion}

\subsection{Conclusion}

Only a few universities in Sichuan open the fancy rope skipping curriculum; compared with the universities in other provinces, the curriculum opening rate is relatively low. Investigated from the teaching staff, schools that open the curriculum, opening methods, survey of project interest, curriculum recognition, implementation of teaching materials, venue and equipment of fancy rope skipping curriculum of regular institutions of higher learning in Sichuan, it is known that they are highly recognizing the fancy rope skipping curriculum; professional teachers of fancy rope skipping are insufficient, so it is difficult for many universities to open the fancy rope skipping curriculum; more good teaching materials are needed.

\subsection{Suggestion}

(1) Enlarge publicity of fancy rope skipping in universities, overcome the difficulties and actively carry it out. At present, the opening ratio of fancy rope skipping curriculum in universities of Sichuan is not that high. From the current situation, leaders of many schools have not attached much importance to fancy rope skipping. Rope is relatively cheap; it is also durable. As long as the school leaders support it and gradually promote it, it will form certain scales. It requires us to enlarge the publicity of fancy rope skipping as well as its related knowledge so as to make more people fully realize the significance and value of fancy rope skipping and actively create conditions for opening fancy rope skipping curriculum.

(2) The curriculum system needs to be boosted in different steps and stages. To learn the guiding thought and target of the curriculum, actively explore the teaching rules of fancy rope skipping curriculum and steadily publicize it is the quality guarantee for universities in Sichuan to carry out the curriculum system of fancy rope skipping. In the implementation process, it needs to combine the development of the times, the actual conditions of the school and the abilities of teachers open or partly open fancy rope skipping curriculum.

(3) Strengthen the related research work of the curriculum system of fancy rope skipping. Construction design of the curriculum system of fancy rope skipping is a complicated work from theory to practice. Curriculum construction, as the most important link of curriculum system, is very important in the implementation process, so it must be deepened and refined. It is suggested to set up the curriculum objects, choose the curriculum contents, formulate the outline and compile the teaching material by centering on the special association and sports institute. In addition, set up fair and reasonable teaching and competition assessment system, explore the viable teaching modes and methods so as to boost the concrete and comprehensive implementation of the curriculum system.

(4) Strengthen cultivation of professional teachers of universities. In order to comprehensively carry out the curriculum system of fancy rope skipping in the universities, construction of teaching power needs to be strengthened. Fancy rope skipping requires correct and clear teaching ideas and teachers of higher professional qualities. Teachers should know more about fancy rope skipping sports, master the skills of related tactics and correctly distinguish the differences between teaching of fancy rope skipping and teaching of other curricula. Gradually strengthen training of related teachers, further strengthen their innovation awareness and improve their business levels and comprehensive abilities. Schools and related functional departments should create the favorable learning 
opportunities and learning environments according to the schedules and targets so as to cultivate a large number of excellent teachers who can adapt to the rapidly developing society. (5) Strengthen construction of teaching materials, making it more professional and pertinent. Teaching material plays a very important role in the process of sports teaching; it is not only the basic condition of teaching, but also the effective carrier of teaching information. According to my investigations, most of the schools adopt the videos of foreign rope skipping teaching to provide training and teaching or the teaching clips made by the rope lovers. Up to now, there is not any teaching material that systematically introduces fancy rope skipping, which is not good for its publicity in universities. In the compilation process of fancy rope skipping, compilers should reasonably choose the contents through combining the characteristics of the times, add the projects of exercise value that pay attention to fitness and teach the self-exercise methods to students and get rid of the old teaching projects.

\section{Reference}

[1] Liu Tongji, Gong Yuan, Ren Junqi. Feasibility Research of Fancy Rope Skipping's Entrance in the Domestic Universities[J]. Sports Culture Guide, Issue 12, 2014

[2] Chen Min. Theoretical Research and
Practice Exploration of Art Sports Curriculum[J]. Nanjing: Nanjing Normal University, 2008

[3] Shen Ying. Analysis and Research of the Current Situation of Fancy Rope Skipping in Some Universities of Anhui[J]. Beijing: China Education Innovation Herald, 2012

[4] Nie Kai. Research of Sports Culture Value of Fancy Rope Skipping[J]. Shaanxi Education (Vocational Education Edition), Issue 06, 2012

[5] Ma Yunpeng. Curriculum and Teaching Theory[M]. Beijing: Central Radio \& TV University Press Co., Ltd, 2002

[6] Zhang Xiumei, Hu Yaohua, Zhao Qi. Feasibility Research of Fancy Rope Skipping Curriculum in Higher Vocational Colleges[J], Issue 07, 2012

[7] Wang Ranke. SWOT Analysis of Fancy Rope Skipping Curriculum in Universities[J]. Journal of Henan Institute of Education (Natural Science Edition), Issue 01, 2014

[8] Qiu Shuang. Feasibility Research of Fancy Rope Skipping Curriculum in Higher Vocational Colleges in Fujian[J]. Journal of Taiyuan City Vocational College, Issue 09, 2014 